\title{
Corynebacterium mustelae sp. nov., isolated from a ferret with lethal sepsis
}

Correspondence

Guido Funke

Idg.funke@t-online.de
Guido Funke, ${ }^{1}$ Reinhard Frodl ${ }^{1}$ and Kathryn A. Bernard ${ }^{2}$

\author{
${ }^{1}$ Department of Medical Microbiology and Hygiene, Gärtner and Colleagues Laboratories, \\ Elisabethenstrasse 11, 88212 Ravensburg, Germany \\ ${ }^{2}$ National Microbiology Laboratory, Public Health Agency of Canada, 1015 Arlington Avenue, \\ Winnipeg, MB R3E 3R2, Canada
}

During the 1990s, only four of the 25 newly defined Corynebacterium species were isolated from animals, whereas, in the last 10 years, nine of the 19 newly defined Corynebacterium species have been isolated from animals. It is generally agreed that the most frequently encountered Corynebacterium species in human clinical specimens are already defined (Funke \& Bernard, 2007), whereas Corynebacterium species isolated from animals have not been systematically investigated. During our ongoing research project on the taxonomy of true Corynebacterium species, we have received a strain with unusual features that was isolated from an animal.

Strain $3105^{\mathrm{T}}$ was cultured from necropsy lung tissue as well as from the liver and kidneys of an approximately 3-yearold male ferret with lethal sepsis. Gram-staining of strain $3105^{\mathrm{T}}$ showed coryneform bacteria arranged in single cells with typical club-shaped elements, but filamentous forms were not observed. The isolate did not stain partially acidfast. When grown aerobically on Columbia sheep blood agar plates (BD) at $35{ }^{\circ} \mathrm{C}$, strain $3105^{\mathrm{T}}$ showed greenishbeige colonies with irregular margins, which are not seen in other true corynebacteria. Characteristically, strain $3105^{\mathrm{T}}$ had a 'humid cellar'-like odour not observed in other coryneform bacteria. In addition, strain $3105^{\mathrm{T}}$ was strongly adherent to agar, a feature that is seen very rarely in true

The GenBank/EMBL/DDBJ accession numbers for the 16S rRNA and partial rpoB gene sequences of strain $3105^{\top}$ are FJ374773 and FJ467330. corynebacteria with the exceptions of Corynebacterium durum, C. freiburgense, C. sundsvallense and C. thomssenii (Funke \& Bernard, 2007; Funke et al., 2009).

Strain $3105^{\mathrm{T}}$ was further screened for chemotaxonomic features and biochemical reactions, applying methods outlined previously (Funke et al., 1993). Chemotaxonomic investigations revealed the presence of meso-diaminopimelic acid as the diamino acid of the peptidoglycan and of mycolic acids, which, together with the negative reaction for partial acid-fastness, were compatible with the assignment of the strain to the genus Corynebacterium (Funke \& Bernard, 2007). The main straight-chain saturated cellular fatty acids were palmitic $(33 \%)$ and stearic $(6 \%)$ acids. Oleic acid $(24 \%)$ was the predominant unsaturated fatty acid and tuberculostearic acid was not detected.

Because of the severe disease of the animal from which strain $3105^{\mathrm{T}}$ had been isolated, we tested the isolate for the presence of the diphtheria toxin gene using the PCR primers Cdipht-1 (5'-ATCCACTTTTAGTGCGAGAACCTTGGTCA-3') and Cdipht-2 (5'-GAAAACTTTTCTTCGTACCACGGGACTAA-3'), as outlined by Nakao \& Popovic (1997). The strain did not harbour this virulence gene.

Because strain $3105^{\mathrm{T}}$ exhibited some phenotypic traits that are not seen in any other presently defined Corynebacterium, we decided to investigate the phylogenetic distinctiveness of strain $3105^{\mathrm{T}}$ by sequencing almost entirely the $16 \mathrm{~S}$ rRNA gene $(>1470 \mathrm{bp})$ according to a 


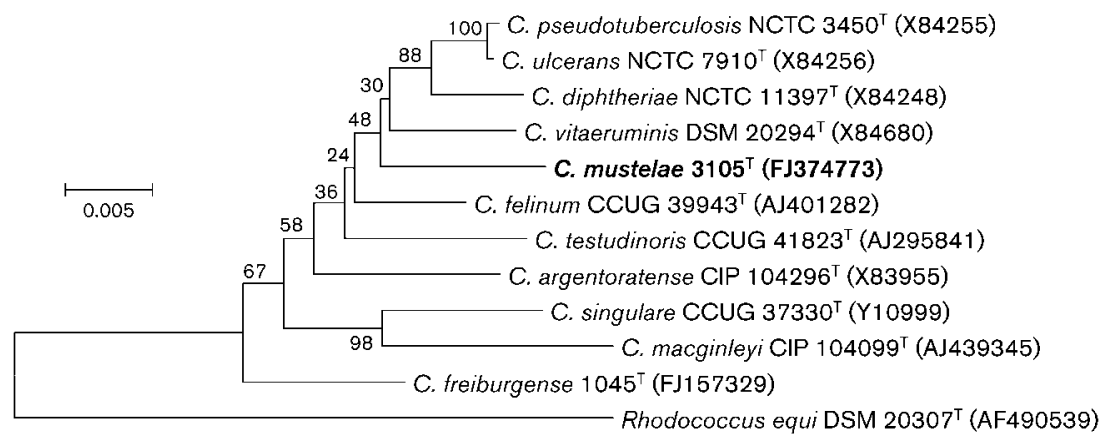

Fig. 1. Neighbour-joining phylogenetic tree based on $16 \mathrm{~S}$ rRNA gene sequences, showing the position of strain $3105^{\top}$ (Corynebacterium mustelae sp. nov.) and its closest phylogenetic neighbours. Percentages at nodes are levels of bootstrap support based on 1000 replications. Rhodococcus equi DSM $20307^{\top}$ was used as an outgroup. Bar, 0.005 substitutions per nucleotide position.

published method (Beck et al., 2008). The BLAST software tool (http://www.ncbi.nlm.nih.gov/blast/Blast.cgi) and the EzTaxon software (Chun et al., 2007) were applied to compare the determined 16S rRNA gene sequence with those of other bacteria. Strain $3105^{\mathrm{T}}$ clustered within the genus Corynebacterium and 16S rRNA gene sequence similarities with the type strains of the 73 presently defined Corynebacterium species ranged from $92.13 \%$ for Corynebacterium glucuronolyticum to $97.12 \%$ for Corynebacterium pseudotuberculosis NCTC $3450^{\mathrm{T}}$. According to the EzTaxon algorithm, the ten closest phylogenetic relatives (including C. pseudotuberculosis) of strain $3105^{\mathrm{T}}$ were the type strains of Corynebacterium vitaeruminis (97.08\% 16S rRNA gene sequence similarity), C. felinum $(96.85 \%)$, C. ulcerans (96.78\%), C. diphtheriae (96.71\%), C. afermentans subsp. lipophilum (96.65\%), C. testudinoris (96.12\%), C. singulare (95.73\%), C. coyleae (95.59\%) and C. striatum (95.58\%). As expected, the nearest other genera were Dietzia, Rhodo- coccus and Tsukamurella, with $16 \mathrm{~S}$ rRNA gene sequence similarities of approximately $92 \%$. If the new $16 \mathrm{~S}$ rRNA gene sequence divergence criterion $(98.7 \%$ cut-off value for species differentiation; Stackebrandt \& Ebers, 2006) is used, it is evident that strain $3105^{\mathrm{T}}$ represents a novel Corynebacterium species.

In order to demonstrate further that strain $3105^{\mathrm{T}}$ represents a hitherto-unknown species, we sequenced a highly variable part of the $r p o B$ gene, as described by Khamis et al. (2004). When comparing this particular part of the $r p o B$ gene sequence of strain $3105^{\mathrm{T}}$ with those from other Corynebacterium species, the type strain of $C$. pseudotuberculosis was again the closest neighbour, with less than $86 \%$ sequence similarity (59 mismatches within $406 \mathrm{bp}$ ), and C. felinum shared less than $85 \%$ similarity.

A 16S rRNA gene sequence phylogenetic tree was constructed using the neighbour-joining method included

Table 1. Characteristics that differentiate strain $3105^{\top}$ from its nearest phylogenetic relatives

Taxa: 1, Corynebacterium mustelae sp. nov. $3105^{\mathrm{T}} ;$, C. diphtheriae; 3, C. felinum; 4, C. pseudotuberculosis; 5, C. ulcerans; 6, C. vitaeruminis. Data for reference species were taken from Collins et al. (2001) and Funke \& Bernard (2007). +, Positive; -, negative; ND, no data available.

\begin{tabular}{|c|c|c|c|c|c|c|}
\hline Characteristic & 1 & 2 & 3 & 4 & 5 & 6 \\
\hline Odour & Humid cellar & - & ND & - & - & - \\
\hline Colony colour* & GNB & WGR & ND & WGR & WGR & $\mathrm{Y}$ \\
\hline Adherence to agar & + & - & $\mathrm{ND}$ & - & - & - \\
\hline \multicolumn{7}{|l|}{ Enzyme activity } \\
\hline Aesculinase & + & - & - & - & - & + \\
\hline Nitrate reductase & - & $+\dagger$ & - & - & - & + \\
\hline Pyrazinamidase & + & - & + & - & - & + \\
\hline Pyrrolidonyl arylamidase & - & - & + & - & - & + \\
\hline Urease & - & - & - & + & + & + \\
\hline Acid production from sucrose & + & $-\ddagger$ & - & - & - & + \\
\hline
\end{tabular}

${ }^{*} \mathrm{GNB}$, Greenish beige; WGR, whitish grey; $\mathrm{Y}$, yellow.

$\dagger$ C. diphtheriae biotype belfanti is negative.

$\ddagger$ Fewer than $1 \%$ of isolates are able to produce acid from sucrose. 
in the MEGA4 software (Tamura et al., 2007), based on a comparison of approximately 1350 nucleotides, with bootstrap analysis (Fig. 1). From the phylogenetic analysis, it is evident that strain $3105^{\mathrm{T}}$ represents a distinct Corynebacterium species. Table 1 outlines the phenotypic features that allow clear differentiation between the novel Corynebacterium strain and its nearest phylogenetic relatives.

Antimicrobial susceptibility testing was performed applying the microdilution method of the Clinical and Laboratory Standards Institute as well as the interpretation guidelines of this organization (CLSI, 2006). Strain $3105^{\mathrm{T}}$ was susceptible to cefotaxime, ciprofloxacin, doxycycline, erythromycin, gentamicin, linezolid, meropenem, penicillin and vancomycin.

The present report provides further evidence that it is unlikely that the heterogeneity of true Corynebacterium species encountered in animals is fully understood. It is not known at present whether transmission of these corynebacteria to humans occurs.

Based on the results of this polyphasic taxonomic study, we propose that strain $3105^{\mathrm{T}}$ is a representative of a novel species of the genus Corynebacterium, Corynebacterium mustelae sp. nov.

\section{Description of Corynebacterium mustelae sp. nov.}

Corynebacterium mustelae (mus.tel'ae. L. n. mustela a weasel, and also a scientific zoological genus name; L. gen. mustelae of a weasel, of Mustela, referring to the isolation of the type strain from a ferret, Mustela putorius furo).

Cells stain Gram-positive and are non-spore-forming, typically club-shaped rods that occur as single cells, in pairs or in small clusters. Colonies are greenish beige, with irregular edges, up to $1-2 \mathrm{~mm}$ in diameter after $48 \mathrm{~h}$ incubation and express a characteristic 'humid cellar'-like odour. Non-lipophilic. Facultatively anaerobic. Catalasepositive. Acid is produced from ribose, glucose, fructose, mannose, $\mathrm{N}$-acetylglucosamine, arbutin, maltose, sucrose, trehalose, gentiobiose, tagatose, L-fucose and 5-ketogluconate, but not from glycerol, erythritol, L-arabinose, xylose, adonitol, methyl $\beta$-xyloside, galactose, sorbose, rhamnose, dulcitol, inositol, mannitol, sorbitol, methyl $\alpha$-D-mannoside, methyl $\alpha$-D-glucoside, amygdalin, salicin, cellobiose, lactose, melibiose, inulin, melezitose, raffinose, starch, glycogen, xylitol, turanose, lyxose, D-fucose, arabitol, gluconate or 2-ketogluconate. Activity of the following enzymes is detected: pyrazinamidase, $\alpha$-glucosidase, aesculinase, esterase (C4), esterase lipase (C8), leucine and cystine arylamidases and phosphoamidase. Activity of the following enzymes is not detected: nitrate reductase, pyrrolidonyl arylamidase, urease, alkaline and acid phosphatases, lipase, valine arylamidase, trypsin, chymotrypsin, $\alpha$ - and $\beta$-galactosidases, $\beta$-glucuronidase, $N$-acetyl- $\beta$ glucosaminidase, $\alpha$-mannosidase and $\alpha$-fucosidase. The Christie-Atkins-Munch-Petersen (CAMP) reaction is negative. The cell wall contains meso-diaminopimelic acid and mycolic acids are also present. The main straight-chain saturated fatty acids are palmitic and stearic acids; the predominant unsaturated fatty acid is oleic acid.

The type strain, $3105^{\mathrm{T}}\left(=\right.$ CCUG $57279^{\mathrm{T}}=\mathrm{DSM} 45274^{\mathrm{T}}$ ), was isolated from necropsy lung tissue of a ferret with lethal sepsis.

\section{References}

Beck, M., Frodl, R. \& Funke, G. (2008). Comprehensive study of strains previously designated Streptococcus bovis consecutively isolated from human blood cultures and emended description of Streptococcus gallolyticus and Streptococcus infantarius subsp. coli. J Clin Microbiol 46, 2966-2972.

Chun, J., Lee, J.-H., Jung, Y., Kim, M., Kim, S., Kim, B. K. \& Lim, Y. W. (2007). EzTaxon: a web-based tool for the identification of prokaryotes based on $16 \mathrm{~S}$ ribosomal RNA gene sequences. Int J Syst Evol Microbiol 57, 2259-2261.

CLSI (2006). Methods for antimicrobial dilution and disk susceptibility testing of infrequently isolated or fastidious bacteria, document M45-A. Wayne, PA: Clinical and Laboratory Standards Institute.

Collins, M. D., Hoyles, L., Hutson, R. A., Foster, G. \& Falsen, E. (2001). Corynebacterium testudinoris sp. nov., from a tortoise, and Corynebacterium felinum sp. nov., from a Scottish wild cat. Int J Syst Evol Microbiol 51, 1349-1352.

Funke, G. \& Bernard, K. A. (2007). Coryneform Gram-positive rods. In Manual of Clinical Microbiology, 9th edn, pp. 485-514. Edited by P. R. Murray, E. J. Baron, J. H. Jorgensen, M. L. Landry \& M. A. Pfaller. Washington, DC: American Society for Microbiology.

Funke, G., Martinetti Lucchini, G., Pfyffer, G. E., Marchiani, M. \& von Graevenitz, A. (1993). Characteristics of CDC group 1 and group 1-like coryneform bacteria isolated from clinical specimens. J Clin Microbiol 31, 2907-2912.

Funke, G., Frodl, R., Bernard, K. A. \& Englert, R. (2009). Corynebacterium freiburgense sp. nov., isolated from a wound after a dog bite. Int J Syst Evol Microbiol 59, 2054-2057.

Khamis, A., Raoult, D. \& La Scola, B. (2004). $r p o B$ gene sequencing for identification of Corynebacterium species. J Clin Microbiol 42, 3925-3931.

Nakao, H. \& Popovic, T. (1997). Development of a direct PCR assay for detection of the diphtheria toxin gene. J Clin Microbiol 35, 16511655.

Stackebrandt, E. \& Ebers, J. (2006). Taxonomic parameters revisited: tarnished gold standards. Microbiol Today 33, 152-155.

Tamura, K., Dudley, J., Nei, M. \& Kumar, S. (2007). MEGA4: molecular evolutionary genetics analysis (MEGA) software version 4.0. Mol Biol Evol 24, 1596-1599. 